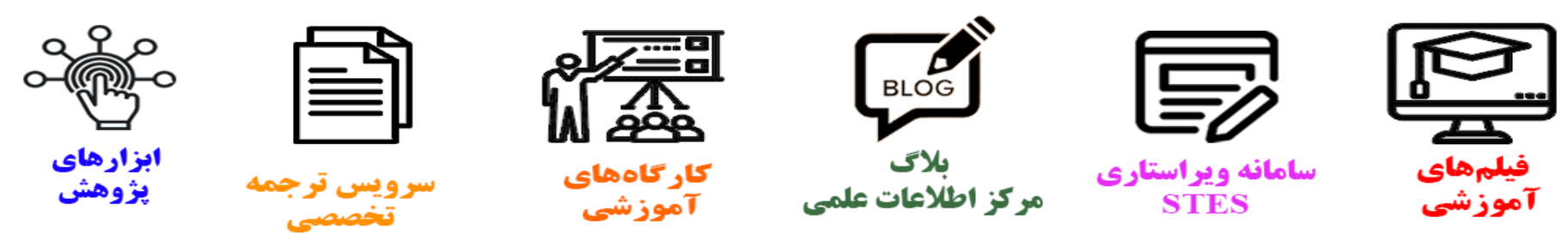

\title{
(c)
}

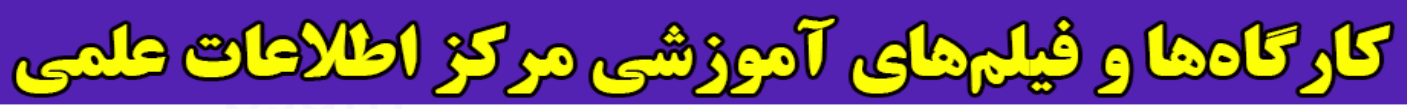
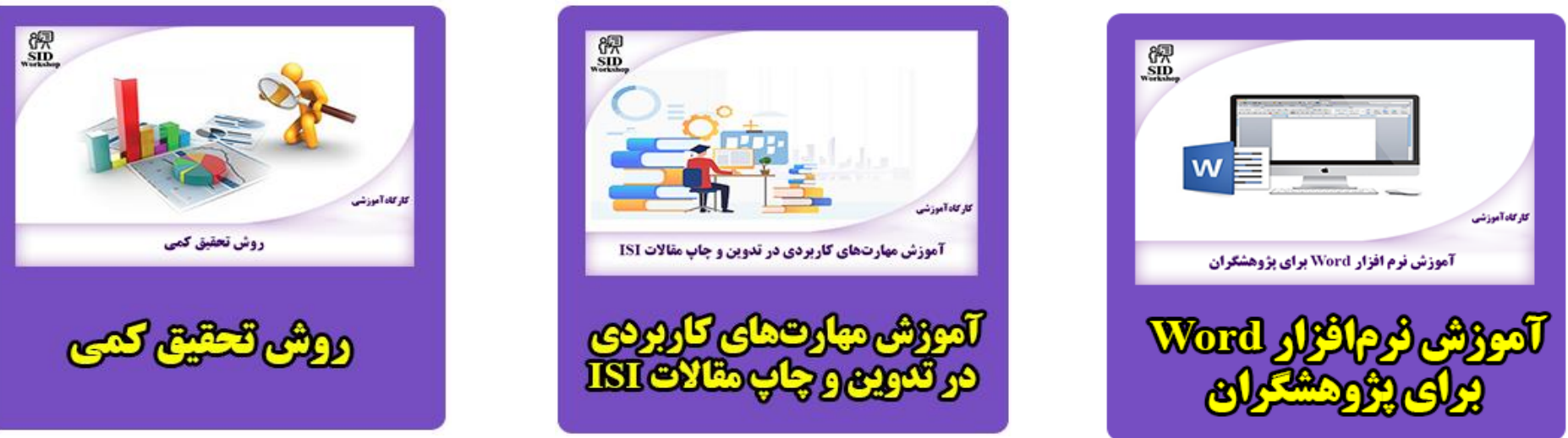


\title{
International Journal of Engineering
}

Journal Hom e page: ww w. ije.ir

\section{Modeling and Availability Analysis of Internet Data Center with various Maintenance Policies}

\author{
D. K. Rawala, M. Ram*b, V. V. Singh ${ }^{c}$ \\ a Department of Mathematics, Mewar University Chittorgarh, Rajasthan, India \\ ${ }^{b}$ Department of Mathematics, Graphic Era University, Dehradun, Uttarakhand, India \\ c Department of Mathematics, Yobe State University, Damaturu, Nigeria
}

\section{$P A P E R \quad I N F O$}

Paper history:

Received 01 March 2013

Received in revised form 19 May 2013

Accepted 22 August 2013

\section{Keywords:}

Reliability Analysis

Internet Data Center (IDC)

Router Failure

Cost Analysis

\section{$A B S T R A C T$}

In this paper, the authors have focused on the stochastic analysis of an internet data center (IDC), which consists of a database main server connected to a redundant server. Observing the different possibilities of functioning of the system, analysis has been done to evaluate the various reliability characteristics of the system. The system can completely fail due to failure of redundant server before repair of database server, router failure and switch failure. The system can also fail completely due to a cooling failure or some natural calamity like earthquake, fire; etc. All the failure rates are assumed constant while the repairs follow two types of distributions namely general and Gumbel-Hougaard family copula.

\section{INTRODUCTION}

The system reliability has been extensively studied by various authors like Cui and $\mathrm{Li}$ [1], Govil [2], Gupta and Sharma [3] and many others. They have discussed the reliability characteristic of complex systems by taking various failures and one repair policy. Network analysis is an important approach to model real-world systems. Considering the present scenario with the complexity of advance technology and modern demands of the networking system, it is necessary to study the internet data center that has become an essential requirement of usual life. Aggrarwal et al. [4] proposed a concept that failure of a node implies the failure of arcs incident from it. Kui et al. [5] studied terminal reliability of a computer communication network. This paper deals with the study of functioning of internet data center (IDC) with a redundant mail server. The internet data center can have two types of failure namely partial failure and complete failure. The information technology enabled architecture of IDC to be handled by two switches $\mathrm{L}_{2}$ and $\mathrm{L}_{3}$. The $\mathrm{L}_{3}$ switch is a six-port switch, connected to a server via $\mathrm{L}_{2}$ switch. Whenever

*Corresponding Author Email: drmrswami@yahoo.com (M. Ram) the main mail server fails, redundant server comes into functioning automatically by a switch over device. The switch over device is instantaneous and automatic. The system can fail due to some failure like

(i) Failure of redundant server before repair of main mail server.

(ii) Failure of switch.

(iii) Router failure.

(iv) Cooling of server failure.

(v) Failure due to a natural calamity like earthquake or fire etc.

The system will be in a degraded state, when the main mail server is in completely failure mode and redundant server is in the partial failure mode.

The authors [6-12] have considered reliability and MTTF of a system, with different types of failures and one type of repair. They discussed the reliability of systems with different failure and common cause failure under the preemptive resume policy using GumbelHougaard family copula distribution. However, there are many situations in real life systems where more than one repair is possible between two transition states. When this possibility exists, reliability of the system can be analyzed with the help of the copula [13, 14]. Therefore, in reference to the earlier models, here the 
authors have considered an internet data center model in which they tried to address the problem where two different repair facilities are available between adjacent states i.e. the initial state and complete failed states. All failure rates are assumed constant. The repairs follow general and Gumbel-Hougaard family copula distributions. In the present paper, $\mathrm{S}_{0}$ is a state where the system is in good working condition. $\mathrm{S}_{1}, \mathrm{~S}_{3}, \mathrm{~S}_{5}$ are states where the system is in degraded mode. States $S_{2}, S_{4}, S_{7}$, $\mathrm{S}_{8}, \mathrm{~S}_{9}$ and $\mathrm{S}_{10}$ are the states where the system is in the complete failure mode. When the redundant server is in degraded state and the repair facility is not available, then system has to wait for repair, which is represented in state $\mathrm{S}_{6}$, and whenever repair facility is available, the system is repaired and is ready for further functioning. Whenever the system is in degraded mode, it is repaired by general repair and whenever the system is in the complete failure mode, the system is repaired with the help of Gumbel-Hougaard family copula. The system is analyzed by supplementary variable technique. The various measures of reliability have been discussed and some particular cases are taken to highlight the result. The transition diagram of the designed model has been shown in Figure 1.

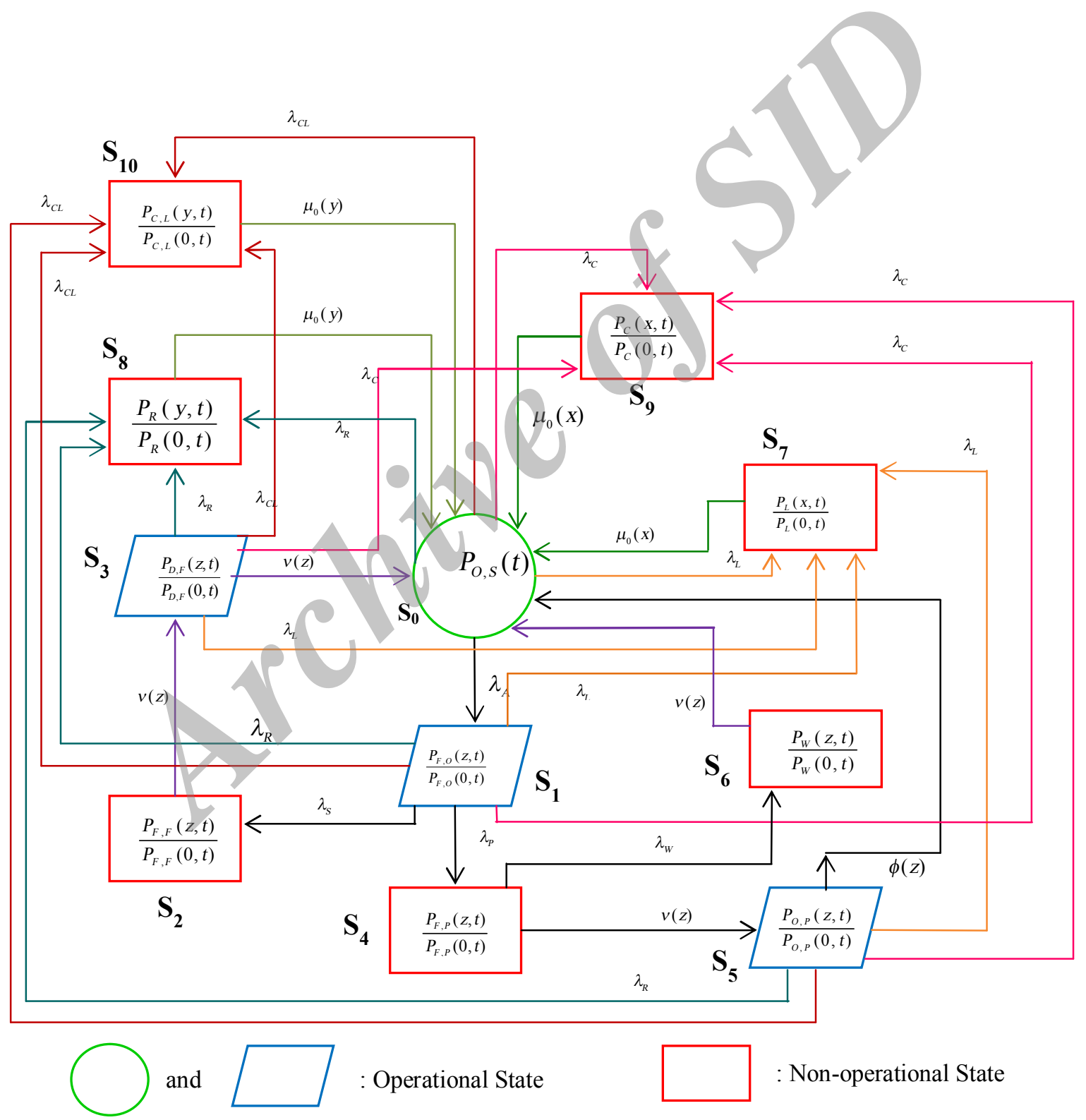

Figure 1. State Transition Diagram 


\section{ASSUMPTIONS}

The following assumptions are taken throughout the discussion of the model:

(i) Initially the system is in $\mathrm{S}_{0}$ state where both main as well as redundant server is in good condition.

(ii) When the main mail server fails, the redundant server starts working and repair is employed to the failed server.

(iii) The system waits for repair, if repair facility is not available; as soon as the repair facility is available, the repairing is employed to failed unit.

(iv) In repair, the preference is given to that unit which has failed first; i. e. main mail server.

(v) All failure rates are constant.

(vi) Switch failure /router failure/ cooling failure/ failure due to natural calamity need fast repairing i. e. Copula distribution is employed to repair (Gumbel-Hougaard family copula).

(vii) Repaired system works like a new and the repair does not damage anything.

\section{NOTATIONS}

The following notations are associated with the model:

$\lambda_{A} / \lambda_{S} / \lambda_{P}$

$/ \lambda_{W} / \lambda_{L} / \lambda_{R}$

$/ \lambda_{C} / \lambda_{C L}$

$\phi(z) / v(z)$

$\bar{P}(s)$

$E_{p}(t)$

$\mathrm{K}_{1}, \mathrm{~K}_{2}$

$\mathrm{C}_{\theta}$

$\left(\mathrm{u}_{1}(\mathrm{p}), \mathrm{u}_{2}(\mathrm{p})\right)$

$P_{o, s}(t)$

$P_{C}(x, t)$
Failure rates of the main mail server/ standby redundant server/ partial failure rate of redundant server/ waiting rate of main mail server/switch failure rate/router failure/cooling failure/failure due to natural calamity.

Repair rates for state $\mathrm{S}_{5} / \mathrm{S}_{2}, \mathrm{~S}_{3}, \mathrm{~S}_{4}, \mathrm{~S}_{6}$.

Laplace transformation of $\mathrm{P}(\mathrm{t})$.

Expected profit during the interval $[0, t)$.

Revenue per unit time and service cost per unit time, respectively.

The expression of joint probability (failed state to the initial state) according to Gumbel-Hougaard family is given as: $C_{\theta}\left(u_{1}(p), u_{2}(p)\right)=\mu_{0}(p)=\exp \left[p^{\theta}+\{\log \phi(p)\}^{\theta}\right]^{1 / \theta}$ Where $\mathrm{u}_{1}(\mathrm{p})=\phi(\mathrm{p})$, and $\mathrm{u}_{2}(\mathrm{p})=\mathrm{e}^{\mathrm{p}} ; \mathrm{p}=\mathrm{x}, \mathrm{y}$.

The probability that the system is in Operable State $\mathrm{S}_{0}$.

The probability that the system is in state $S_{9}$, the system is in complete failed state due to the failure of cooling system. The system is under repair and the elapse repair time is $\mathrm{x}$, $\mathrm{t}$.
$P_{L}(x, t) \quad$ The probability that the system is in state $\mathrm{S}_{7}$, the system is in complete failed state due to the switch failure. The system is under repair and the elapse repair time is $\mathrm{x}, \mathrm{t}$.

$P_{C, L}(y, t) \quad$ The probability that the system is in state $\mathrm{S}_{10}$ the system is in complete failed state due to the natural calamity. The system is under repair and the elapse repair time is $\mathrm{y}, \mathrm{t}$.

$P_{R}(y, t) \quad$ The probability that the system is in state $\mathrm{S}_{8}$, the system is in complete failed state due to the router failure. The system is under repair and the elapse repair time is $\mathrm{y}, \mathrm{t}$.

$P_{O, F}(z, t) \quad$ The probability that the system is in state $\mathrm{S}_{3}$, the system is in a degraded state and is in the operational state after repair of the main mail server. The redundant server is running under repair and the elapse repair time is $\mathrm{z}, \mathrm{t}$.

$P_{F, F}(z, t) \quad$ The probability that the system is in state $\mathrm{S}_{2}$ the system is in complete failed state due to the failure of redundant server before repair of the main mail server. The main mail server is running under repair and the elapse repair time is $\mathrm{z}, \mathrm{t}$.

$P_{F, O}(z, t) \bigcirc$ The probability that the system is in state $\mathrm{S}_{1}$ after failure of the main mail server. The system is in degraded state but is in operational state. The system is under repair and the elapse repair time is $\mathrm{z}, \mathrm{t}$.

$P_{F, P}(z, t) \quad$ The probability that the system is in state $\mathrm{S}_{4}$ ,the system is in complete failed state due to failure of main mail server and partial failure in redundant server, the main mail server is running under repair and the elapse repair time is $\mathrm{z}, \mathrm{t}$.

$P_{O P}(z, t) \quad$ The probability that the system is in state $\mathrm{S}_{5}$, the system is in the operational state as the main mail server has been repaired and is in operational state. The redundant server is running under repair and the elapse repair time is $\mathrm{z}, \mathrm{t}$.

$P_{W}(z, t) \quad$ The probability that the system is in state $\mathrm{S}_{6}$, the system is in failed state after a failure of the main mail server. The system is under repair and the elapse repair time is $\mathrm{z}, \mathrm{t}$.

\section{FORMULATION AND SOLUTION OF MATHEMATICAL MODEL}

By the probability of considerations and continuity arguments, we can obtain the following set of difference 
differential equations governing the present mathematical model.

$$
\begin{aligned}
& {\left[\frac{\partial}{\partial t}+\lambda_{\mathrm{A}}+\lambda_{L}+\lambda_{C}+\lambda_{C L}+\lambda_{R}\right] P_{O, S}(t)} \\
& =\left[\int_{0}^{\infty} v(z) P_{W}(z, t) d z+\int_{0}^{\infty} \phi(z) P_{O, P}(z, t) d z\right. \\
& +\int_{0}^{\infty} \mu_{o}(x) P_{C}(x, t) d x+\int_{0}^{\infty} \mu_{0}(y) P_{C L}(y, t) d y \\
& +\int_{0}^{\infty} v(z) P_{O, F}(z, t) d z+\int_{0}^{\infty} \mu_{o}(x) P_{L}(x, t) d x \\
& +\int_{0}^{\infty} \mu_{o}(y) P_{R}(y, t) d y \\
& {\left[\frac{\partial}{\partial t}+\frac{\partial}{\partial x}+\lambda_{R}+\lambda_{C}+\lambda_{L}+\lambda_{C L}+\lambda_{S}+\lambda_{P}\right] P_{F, O}(z, t)=0} \\
& {\left[\frac{\partial}{\partial t}+\frac{\partial}{\partial z}+v(z)\right] P_{F, F}(z, t)=0} \\
& {\left[\frac{\partial}{\partial t}+\frac{\partial}{\partial z}+\lambda_{R}+\lambda_{C}+\lambda_{L}+\lambda_{C L}+v(z)\right] P_{O, F}(z, t)=0} \\
& {\left[\frac{\partial}{\partial t}+\frac{\partial}{\partial z}+v(z)+\lambda_{W}\right] P_{F, P}(z, t)=0} \\
& {\left[\frac{\partial}{\partial t}+\frac{\partial}{\partial z}+\lambda_{R}+\lambda_{C}+\lambda_{L}+\lambda_{C L}+\phi(z)\right] P_{O, P}(z, t)=0} \\
& {\left[\frac{\partial}{\partial t}+\frac{\partial}{\partial z}+v(z)\right] P_{W}(z, t)=0} \\
& {\left[\frac{\partial}{\partial t}+\frac{\partial}{\partial x}+\mu_{0}(x)\right] P_{L}(x, t)=0} \\
& {\left[\frac{\partial}{\partial t}+\frac{\partial}{\partial x}+\mu_{0}(x)\right] P_{C}(x, t)=0} \\
& {\left[\frac{\partial}{\partial t}+\frac{\partial}{\partial y}+\mu_{0}(y)\right] P_{R}(y, t)=0} \\
& {\left[\frac{\partial}{\partial t}+\frac{\partial}{\partial y}+\mu_{0}(y)\right] P_{C L}(y, t)=0}
\end{aligned}
$$

Boundary conditions

$$
\begin{aligned}
& P_{F, O}(0, t)=\lambda_{A} P_{O, S}(t) \\
& P_{F, F}(0, t)=\lambda_{S} \lambda_{A} P_{O, S}(t) \\
& P_{O, F}(0, t)=\int_{0}^{\infty} v(z) P_{F, F}(z, t) d z \\
& P_{F, P}(0, t)=\lambda_{P} \lambda_{A} P_{O, S}(t)
\end{aligned}
$$

$$
\begin{aligned}
& P_{O, P}(0, t)=\int_{0}^{\infty} v(z) P_{F, P}(z, t) d z \\
& P_{W}(0, t)=\lambda_{W} \lambda_{P} \lambda_{A} P_{O, S}(t) \\
& P_{L}(0, t)=\lambda_{C L}\left(P_{O, S}(t)+P_{O, P}(0, t)+P_{O, F}(0, t)+P_{F, O}(0, t)\right) \\
& P_{R}(0, t)=\lambda_{R}\left(P_{O, S}(t)+P_{O, P}(0, t)+P_{O, F}(0, t)+P_{F, O}(0, t)\right) \\
& P_{C}(0, t)=\lambda_{C}\left(P_{O, S}(t)+P_{O, P}(0, t)+P_{O, F}(0, t)+P_{F, O}(0, t)\right) \\
& P_{C L}(0, t)=\lambda_{C L}\left(P_{O, S}(t)+P_{O, P}(0, t)+P_{O, F}(0, t)+P_{F, O}(0, t)\right)
\end{aligned}
$$

Initials condition

$P_{O, S}(0)=1$ and other state probabilities at $\mathrm{t}=0$ are zero.

Taking Laplace transformation of equations (1)-(21) and using equation (22), we obtain

$$
\left[s+\lambda_{A}+\lambda_{L}+\lambda_{C}+\lambda_{C L}+\lambda_{R}\right] \bar{P}_{O, S}(s)
$$

$$
=1+\int_{0}^{\infty} v(z) \bar{P}_{W}(z, s) d z+\int_{0}^{\infty} \phi(z) \bar{P}_{O, P}(z, s) d z
$$

$+\int_{0}^{\infty} \mu_{o}(x) \bar{P}_{C}(x, s) d x+\int_{0}^{\infty} \mu_{0}(y) \bar{P}_{C L}(y, s) d y$

$+\int_{0}^{\infty} v(z) \bar{P}_{O, F}(z, s) d z+\int_{0}^{\infty} \mu_{o}(x) \bar{P}_{L}(x, s) d x$

$+\int_{0}^{\infty} \mu_{o}(y) \bar{P}_{R}(y, s) d y$

$$
\left[s+\frac{\partial}{\partial z}+\lambda_{S}+\lambda_{C L}+\lambda_{C}+\lambda_{L}+\lambda_{R}+\lambda_{P}\right] \bar{P}_{F, O}(z, s)=0
$$

$\left[s+\frac{\partial}{\partial z}+v(z)+\lambda_{W}\right] \bar{P}_{F, P}(z, s)=0$

$\left[s+\frac{\partial}{\partial v}+\lambda_{L}+\lambda_{C}+\lambda_{C L}+\lambda_{R}+\phi(z)\right] \bar{P}_{O, P}(z, s)=0$

$\left[s+\frac{\partial}{\partial z}+v(z)\right] \bar{P}_{w}(z, s)=0$

$\left[s+\frac{\partial}{\partial x}+\mu_{0}(x)\right] \bar{P}_{L}(x, s)=0$

$\left[s+\frac{\partial}{\partial x}+\mu_{0}(x)\right] \bar{P}_{C}(x, s)=0$ 


$$
\begin{aligned}
& {\left[s+\frac{\partial}{\partial y}+\mu_{0}(y)\right] \bar{P}_{R}(y, s)=0} \\
& {\left[s+\frac{\partial}{\partial y}+\mu_{0}(y)\right] \bar{P}_{C L}(y, s)=0} \\
& \bar{P}_{F, O}(0, s)=\lambda_{A} \bar{P}_{O, S}(s) \\
& \bar{P}_{F, F}(0, s)=\lambda_{s} \lambda_{A} \bar{P}_{O, S}(s) \\
& \bar{P}_{O, F}(0, s)=\int_{0}^{\infty} v(z) \bar{P}_{F, F}(z, s) d z \\
& \bar{P}_{O, P}(0, s)=\int_{0}^{\infty} v(z) \bar{P}_{F, P}(z, s) d z \\
& \bar{P}_{F, P}(0, s)=\lambda_{p} \lambda_{A} \bar{P}_{O, S}(s) \\
& \bar{P}_{L}(0, s)=\lambda_{L}\left(\bar{P}_{O, S}(s)+\bar{P}_{F, O}(0, s)+\bar{P}_{O, P}(0, s)+\bar{P}_{O, F}(0, s)\right) \\
& \bar{P}_{R}(0, s)=\lambda_{R}\left(\bar{P}_{O, S}(s)+\bar{P}_{F, O}(0, s)+\bar{P}_{O, P}(0, s)+\bar{P}_{O, F}(0, s)\right) \\
& \bar{P}_{W}(0, s)=\lambda_{W} \lambda_{P} \lambda_{A} \bar{P}_{O, S}(s) \\
& \bar{P}_{C}(0, s)=\lambda_{C}\left(\bar{P}_{O, S}(s)+\bar{P}_{F, O}(0, s)+\bar{P}_{O, P}(0, s)+\bar{P}_{O, F}(0, s)\right)
\end{aligned}
$$

$$
\bar{P}_{C L}(0, s)=\lambda_{C L}\left(\bar{P}_{O, S}(s)+\bar{P}_{F, O}(0, s)+\bar{P}_{O, P}(0, s)+\bar{P}_{O, F}(0, s)\right)
$$

Solving (23) -(33) with the help of (34) -(43), one may get

$$
\bar{P}_{O, S}(s)=\frac{1}{D(s)}
$$

$\bar{P}_{F, O}(s)=\frac{\lambda_{A}}{D(s)\left(s+\lambda_{P}+\lambda_{S}+\lambda_{C}+\lambda_{C L}+\lambda_{R}+\lambda_{L}\right)}$

$\bar{P}_{O, F}(s)=\frac{\lambda_{A} \lambda_{S}}{D(s)} s_{v}\left(s+\lambda_{C}+\lambda_{C L}+\lambda_{R}+\lambda_{L}\right)$

$\bar{P}_{F, F}(s)=\frac{\lambda_{A} \lambda_{S}}{D(s)} \frac{\left(1-S_{v}(s)\right)}{s}$

$$
\bar{P}_{F, P}(s)=\frac{\lambda_{A} \lambda_{P}}{D(s)} \frac{\left(1-S_{v}\left(s+\lambda_{W}\right)\right)}{s+\lambda_{W}}
$$

$$
\begin{aligned}
& \bar{P}_{O, P}(s)=\frac{\lambda_{A} \lambda_{P}}{D(s)} S_{v}\left(s+\lambda_{W}\right) \frac{\left(1-S_{\phi}\left(s+\lambda_{C}+\lambda_{C L}+\lambda_{L}+\lambda_{R}\right)\right)}{s+\lambda_{C}+\lambda_{C L}+\lambda_{L}+\lambda_{R}} \\
& \bar{P}_{W}(s)=\frac{\lambda_{W} \lambda_{P} \lambda_{A}}{D(s)} \frac{\left(1-S_{v}(s)\right)}{s}
\end{aligned}
$$

$\bar{P}_{L}(s)=\frac{\lambda_{L}\left(1+\lambda_{A}+\lambda_{A} \lambda_{P} S_{V}\left(s+\lambda_{W}\right) S_{V}(s)+\lambda_{A} \lambda_{S} S_{V}(s)\right)}{D(s)} \frac{\left(1-S_{\mu_{0}}(s)\right)}{s}$

$\bar{P}_{C}(s)=\frac{\lambda_{C}\left(1+\lambda_{A}+\lambda_{A} \lambda_{P} S_{v}\left(s+\lambda_{W}\right) S_{v}(s)+\lambda_{A} \lambda_{s} S_{v}(s)\right)}{D(s)} \frac{\left(1-S_{\mu_{0}}(s)\right)}{s}$

$\bar{P}_{C L}(s)=\frac{\lambda_{C L}\left(1+\lambda_{A}+\lambda_{A} \lambda_{P} S_{v}\left(s+\lambda_{W}\right) S_{V}(s)+\lambda_{A} \lambda_{S} S_{v}(s)\right)}{D(s)} \frac{\left(1-S_{\mu_{0}}(s)\right)}{s}$

$\bar{P}_{R}(s)=\frac{\lambda_{R}\left(1+\lambda_{A}+\lambda_{A} \lambda_{P} S_{V}\left(s+\lambda_{W}\right) S_{V}(s)+\lambda_{A} \lambda_{S} S_{v}(s)\right)}{D(s)} \frac{\left(1-S_{\mu_{0}}(s)\right)}{s}$

Where

$$
D(s)=\left(\begin{array}{l}
s+\lambda_{\mathrm{A}}+\lambda_{L}+\lambda_{C}+\lambda_{C L}+\lambda_{R}-\left(\lambda_{W} \lambda_{P} \lambda_{A} S_{v}(s)+\lambda_{P} \lambda_{A} S_{v}\left(s+\lambda_{W}\right) S_{\phi}\left(s+\lambda_{C}+\lambda_{L}+\lambda_{R}+\lambda_{C L}\right)\right. \\
+\lambda_{C}\left(1+\lambda_{A}+\lambda_{A} \lambda_{P} S_{v}\left(s+\lambda_{W}\right) S_{v}(s)+\lambda_{A} \lambda_{S} S_{v}(s)\right) S_{\mu_{0}}(s)+\lambda_{C L}\left(\left(1+\lambda_{A}+\lambda_{A} \lambda_{P} S_{v}\left(s+\lambda_{W}\right) S_{v}(s)\right.\right. \\
\left.+\lambda_{A} \lambda_{S} S_{v}(s)\right) S_{\mu_{0}}(s)+\lambda_{S} \lambda_{A} S_{v}\left(s+\lambda_{L}+\lambda_{C}+\lambda_{C L}+\lambda_{R}\right) S_{\mu_{0}}(s)+\lambda_{L}\left(\left(1+\lambda_{A}+\lambda_{A} \lambda_{P} S_{v}\left(s+\lambda_{W}\right) S_{v}(s)\right.\right. \\
\left.\left.+\lambda_{A} \lambda_{S} S_{v}(s)\right)\right) S_{\mu_{0}}(s)+\lambda_{R}\left(\left(1+\lambda_{A}+\lambda_{A} \lambda_{P} S_{v}\left(s+\lambda_{W}\right) S_{v}(s)+\lambda_{A} \lambda_{S} S_{v}(s) S_{\mu_{0}}(s)\right)\right.
\end{array}\right)
$$

The Laplace transformations of the probabilities that the system is in up (i.e. either good or degraded state) and failed state at any time are as follows:

$$
\begin{aligned}
& \bar{P}_{u p}(s)=\bar{P}_{O, S}(s)+\bar{P}_{F, O}(s)+\bar{P}_{O, F}(s)+\bar{P}_{O, P}(s) \\
& \bar{P}_{\text {failed }}(s)=\bar{P}_{F, F}(s)+\bar{P}_{w}(s)+\bar{P}_{L}(s)+\bar{P}_{C}(s)+\bar{P}_{C L}(s)+\bar{P}_{R}(s)+\bar{P}_{F, P}(s)
\end{aligned}
$$

\section{PARTICULAR CASES}

5. 1. Availability exponential

$S_{\mu_{0}}(s)=\bar{S}$
When repair follows an distribution, setting $(s)=\frac{\exp \left[x^{\theta}+\{\log \phi(x)\}^{\theta}\right]^{1 / \theta}}{s+\exp \left[x^{\theta}+\{\log \phi(x)\}^{\theta}\right]^{1 / \theta}}$ 
$, \bar{S}_{v}(s)=\frac{v}{s+v}, \bar{S}_{\phi}(s)=\frac{\phi}{s+\phi}$ and the values of different parameters are $\lambda_{A}=0.01, \quad \lambda_{S}=0.015, \quad \lambda_{P}=0.02$, $\lambda_{W}=0.025, \quad \lambda_{L}=0.03, \quad \lambda_{C}=0.035, \lambda_{C L}=0.022$, $\lambda_{R}=0.04, \quad \phi(v)=1, v(z)=1, \quad \phi=1, \theta=1$ in (55)

5. 1. 1. Expression for availability, when repair follows general and Gumbel-Hougaard family copula time distribution.

$$
P_{u p}(t)=\left(\begin{array}{l}
-0.06177729500 \mathrm{e}^{(-0.162000 t)} \\
+0.04513535841 \mathrm{e}^{(-2.846875602 t)} \\
+0.001402599367 \mathrm{e}^{(-1.125568762 t)} \\
-0.0011622793492 \mathrm{e}^{(-1.025325698 t)} \\
+0.35990465 \mathrm{e}^{(-1.001537909 t)} \\
+1.016398532 \mathrm{e}^{(-0.007992029066 t)}
\end{array}\right)
$$

5. 1. 2. Expression for availability, when repair follows the general time distribution.

$P_{u p}(t)=\left(\begin{array}{l}-0.05605364342 \mathrm{e}^{(-0.162000 t)} \\ +0.1118791750 \mathrm{e}^{(-1.129144601 t)} \cos (0.01495793895 t) \\ -0.02613259173 \mathrm{e}^{(-1.129144601 t)} \sin (0.01495793895 t) \\ +0.002237256039 \mathrm{e}^{(-1.011595711 t)} \cos (0.007838586453 t) \\ -0.002048265310 \mathrm{e}^{(-1.011595711 t)} \sin (0.007838586453 t) \\ +0.9419372123 \mathrm{e}^{(-0.0075193731 t)}\end{array}\right)$

$(57 \mathrm{~b})$

For, $\mathrm{t}=0,1,2,3,4,5,6,7,8,9$ and so on, one may get different values of $\mathrm{P}_{\mathrm{up}}(\mathrm{t})$ as shown in Table 1

5. 2. Mean Time to Failure (MTTF) Taking all repairs to zero in the Equation (55). Taking the limit as $s$ tends to zero, one can obtain the MTTF as:

$$
\text { MTTF }=\frac{1}{\left(\lambda_{A}+\lambda_{C}+\lambda_{L}+\lambda_{C L}+\lambda_{R}\right)}\left(1+\frac{\lambda_{A}}{\left(\lambda_{P}+\lambda_{C}+\lambda_{L}+\lambda_{C L}+\lambda_{R}+\lambda_{S}\right)}\right)
$$

Setting $\quad \lambda_{A}=0.01, \lambda_{L}=0.03 \lambda_{C}=0.035, \lambda_{C L}=0.022$, $\lambda_{R}=0.04, \lambda_{P}=0.02 \lambda_{S}=0.015$ and varying $\lambda_{\mathrm{A}}, \lambda_{\mathrm{L}}$, $\lambda_{\mathrm{C}}, \lambda_{\mathrm{CL}}, \lambda_{\mathrm{R}}, \lambda_{\mathrm{P}}, \lambda_{\mathrm{S}}$ as $0.01,0.02,0.03,0.04,0.05,0.06$, $0.07,0.08,0.09$ one by one in (58). One may obtain the Table 2, which demonstrates the variation of MTTF with respect to failure rates.

5. 3. Cost Analysis Let the service facility be always available, then expected profit during the interval $[0, t)$ is

$$
E_{p}(t)=K_{1} \int_{0}^{t} P_{u p}(t) d t-K_{2} t
$$

Using (57 a) in (59), the expected profit of the system is given by

$$
E_{p}(t)=\left(\begin{array}{l}
K_{1}\left(-0.005516 \mathrm{e}^{(-2.7607 t)} 0.00090376 \mathrm{e}^{(-1.2227 t)}\right. \\
-0.000021733 \mathrm{e}^{(-1.0563 t)}-639.21 \mathrm{e}^{(0.0015579 t)} \\
+639.21)-K_{2} t
\end{array}\right)
$$

Setting $\mathrm{K}_{1}=1$ and $\mathrm{K}_{2}=0.5,0.4,0.3,0.2,0.1,0.05$, 0.01 , respectively and varying $\mathrm{t}=0,1,2,3,4,5,6,7,8$, 9 and so on units of time in (60), one get Table 3 .

TABLE 1. Time vs. Availability

\begin{tabular}{ccc}
\hline \multirow{2}{*}{ Time(t) } & \multicolumn{2}{c}{$\mathbf{P}_{\text {up }}(\mathbf{t})$} \\
\cline { 2 - 3 } & Case 5. 1. 1 & Case 5. 1.2 \\
\hline 0 & 1.0000 & 1.0000 \\
1 & 0.9584 & 0.9241 \\
2 & 0.9558 & 0.8992 \\
3 & 0.9543 & 0.8930 \\
4 & 0.9521 & 0.8859 \\
5 & 0.9491 & 0.8826 \\
6 & 0.9454 & 0.8756 \\
7 & 0.9412 & 0.8716 \\
8 & 0.9365 & 0.8672 \\
9 & 0.9315 & 0.8626 \\
\hline
\end{tabular}

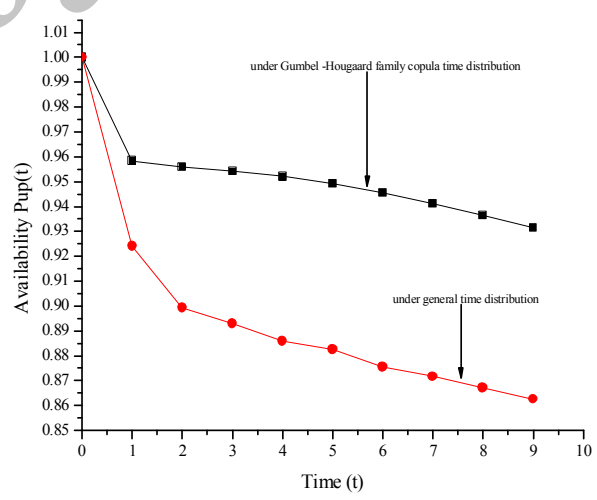

Figure 2. Time vs. Availability

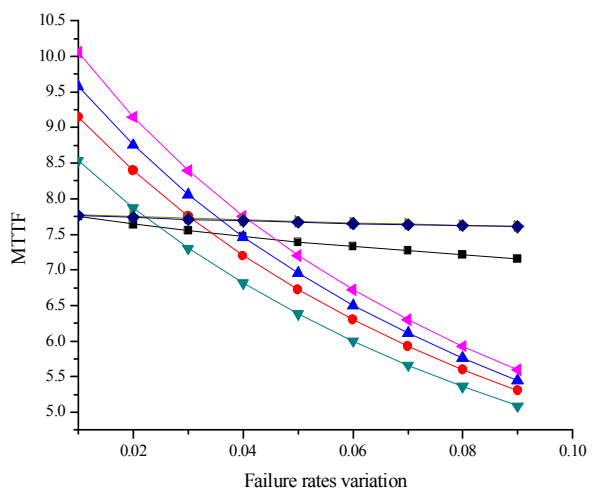

Figure 3. MTTF as function of Failure rate 
TABLE 2. Failure rates vs. MTTF

\begin{tabular}{|c|c|c|c|c|c|c|c|}
\hline \multirow{2}{*}{ Failure rate } & \multicolumn{7}{|c|}{ MTTF with respect to } \\
\hline & $\lambda_{A}$ & $\lambda_{L}$ & $\lambda_{C}$ & $\lambda_{C L}$ & $\lambda_{R}$ & $\lambda_{P}$ & $\lambda_{S}$ \\
\hline 0.01 & 7.7498 & 9.1489 & 9.5802 & 8.5333 & 10.0538 & 7.7794 & 7.7642 \\
\hline 0.02 & 7.6425 & 8.3920 & 8.7543 & 7.8704 & 9.1489 & 7.7498 & 7.7363 \\
\hline 0.03 & 7.5489 & 7.7498 & 8.0583 & 7.3022 & 8.3920 & 7.7236 & 7.7116 \\
\hline 0.04 & 7.4665 & 7.1982 & 7.4639 & 6.8100 & 7.7498 & 7.7003 & 7.6896 \\
\hline 0.05 & 7.3934 & 6.7193 & 6.9564 & 6.3795 & 7.1982 & 7.6794 & 7.6697 \\
\hline 0.06 & 7.3281 & 6.2999 & 6.5029 & 6.0000 & 6.7193 & 7.6606 & 7.6519 \\
\hline 0.07 & 7.2695 & 5.9292 & 6.1091 & 5.6628 & 6.2999 & 7.6435 & 7.6356 \\
\hline 0.08 & 7.2165 & 5.5998 & 5.7599 & 5.3613 & 5.9294 & 7.6280 & 7.6208 \\
\hline 0.09 & 7.1584 & 5.3047 & 5.4483 & 5.0901 & 5.5998 & 7.6138 & 7.6072 \\
\hline
\end{tabular}

TABLE 3. Time vs. Expected profit

\begin{tabular}{|c|c|c|c|c|c|c|c|}
\hline \multirow{2}{*}{ Time(t) } & \multicolumn{5}{|c|}{ Ep(t) } & \\
\hline & $K_{2}=0.5$ & $K_{2}=0.4$ & $K_{2}=0.3$ & $K_{2}=0.2$ & $K_{2}=0.1$ & $K_{2}=0.05$ & $K_{2}=0.01$ \\
\hline 0 & 0 & 0 & 0 & 0 & 0 & 0 & 0 \\
\hline 1 & 0.4703 & 0.5703 & 0.6703 & 0.7703 & 0.8703 & 0.9203 & 0.9603 \\
\hline 2 & 0.9269 & 1.1269 & 1.3269 & 1.5269 & 1.7269 & 1.8269 & 1.9069 \\
\hline 3 & 1.3820 & 1.6820 & 1.9820 & 2.2820 & 2.5820 & 2.7330 & 2.8520 \\
\hline 4 & 1.8353 & 2.2353 & 2.6353 & 3.0353 & 3.4353 & 3.6353 & 3.7953 \\
\hline 5 & 2.2660 & 2.7860 & 3.2860 & 3.7860 & 4.2860 & 4.5360 & 4.7360 \\
\hline 6 & 2.7333 & 3.3333 & 3.9333 & 4.5333 & 5.1333 & 5.4333 & 5.6733 \\
\hline 7 & 3.1767 & 3.8767 & 4.5767 & 5.2767 & 5.9767 & 6.3267 & 6.6067 \\
\hline 8 & 3.6156 & 4.4156 & 5.2156 & 6.0156 & 6.8156 & 7.2156 & 7.5356 \\
\hline 9 & 4.0496 & 4.9496 & 5.8496 & 6.7496 & 7.6496 & 8.0996 & 8.4896 \\
\hline
\end{tabular}

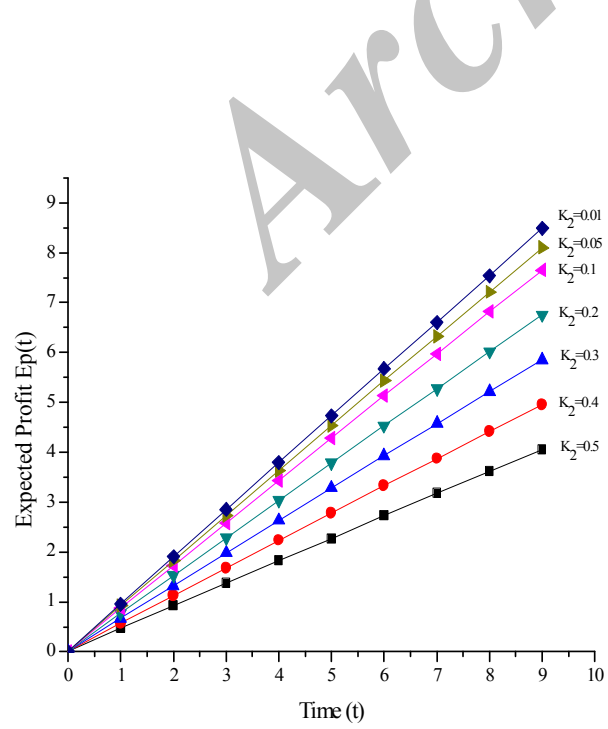

Figure 4. Time vs. Expected profit

\section{DISCUSSION AND CONCLUSION}

Table 1 and Figure 2 show information how availability of the complex repairable system changes with respect to the time when failure rates are fixed at different values. When failure rates are fixed at lower values $\lambda_{A}=0.01$, $\lambda_{S}=0.015, \lambda_{P}=0.02, \lambda_{W}=0.025, \lambda_{L}=0.03, \lambda_{C}=0.035$, $\lambda_{C L}=0.022, \lambda_{R}=0.04$ the availability of the system decreases. Probability of failure also increases, with the passage of time and ultimately becomes steady to the value zero after a sufficient long interval of time. Hence, one can safely predict the future behavior of a complex system at any time for any given set of parametric values, as is evident by the graphical consideration of the model.

Furthermore, availability of the system can be obtained with the help of copula distribution and general distribution in repair as per Equations (57 a) and (57 b), respectively and found that copula distribution improve availability of the system. 
Table 2 and corresponding Figure 2 yields the meantime-to-failure (MTTF) of the system with respect to variation in $\lambda_{\mathrm{A}}, \lambda_{\mathrm{C}}, \lambda_{\mathrm{CL}}, \lambda_{\mathrm{R}}, \lambda_{\mathrm{P}}, \lambda_{\mathrm{S}}$ and $\lambda_{\mathrm{L}}$ respectively when other parameters have been taken as constant.

When revenue cost per unit time $\mathrm{K}_{1}$ fixed at 1 , service $\operatorname{cost} \mathrm{K}_{2}=0.5,0.4,0.3,0.2,0.1,0.05,0.01$, profit has been calculated. Results are also demonstrated by the graphs. It can be observed from Table 3 and corresponding Figure 4 that as service cost decreases, profit increases.

Hence, this modeling is very useful in engineering problems and copula applications in reliability theory.

\section{REFERENCE}

1. Cui, L. and Li, H., "Analytical method for reliability and MTTF assessment of coherent systems with dependent components", Reliability Engineering \& System Safety, Vol. 92, No. 3, (2007), 300-307.

2. Govil, A. K., "Operational behaviour of a complex system having shelf-life of the components under preemptive resume repair discipline", Microelectronics Reliability, Vol. 13, No. 2, (1974), 97-101.

3. Gupta, P. P. and Sharma, M. K., "Reliability and MTTF evaluation of a two duplex-unit standby system with two types of repair", Microelectronics Reliability, Vol. 33, No. 3, (1993), 291-295.

4. Aggarwal, K. K., Gupta, J. S. and Misra, K. B., "A simple method for reliability evaluation of a communication system", Communications, IEEE Transactions on, Vol. 23, No. 5, (1975), 563-566.

5. Kiu, S.-W. and McAllister, D. F., "Reliability optimization of computer-communication networks", Reliability, IEEE Transactions on, Vol. 37, No. 5, (1988), 475-483.
6. Ram, M. and Singh, S. B., "Analysis of a complex system with common cause failure and two types of repair facilities with different distributions in failure", International Journal of Reliability and Safety, Vol. 4, No. 4, (2010), 381-392.

7. Ram, M. and Singh, S. B., "Availability, MTTF and cost analysis of complex system under preemptive-repeat repair discipline using Gumbel-Hougaard family copula", International Journal of Quality \& Reliability Management, Vol. 27, No. 5, (2010), 576-595.

8. Ram, M. and Singh, S. B., "Analysis of reliability characteristics of a complex engineering system under copula", Journal of Reliability and Statistical Studies, Vol. 2, No. 1, (2009), 91102.

9. Ram, M. and Singh, S. B., "Availability and cost analysis of a parallel redundant complex system with two types of failure under preemptive-resume repair discipline using GumbelHougaard family copula in repair", International Journal of Reliability, Quality and Safety Engineering, Vol. 15, No. 04, (2008), 341-365.

10. Singh, S. B., Gupta, P. P. and Goel, C. K., "Analytical study of a complex stands by redundant systems involving the concept of multi-failure human failure under head-of-line repair policy", Bull Pure Appl Sci, Vol. 20, No. 2, (2001), 345-351.

11. Singh, V. V., Singh, S. B., Ram, M. and Goel, C. K., "Availability, MTTF and cost analysis of a system having two units in series configuration with controller", International Journal of System Assurance Engineering and Management, Vol.4, No.2, (2012), 341-352

12. Singh, V. V, Singh, S. B., Ram, M. and Goel, C. K., " Availability analysis of a system having three units super priority, priority and ordinary under preemptive resume repair policy ", International Journal of Reliability and Applications, Vol. 11, No. 1, (2010), 41-53.

13. Melchiori, M., "Which Archimedean copula is the right one?", YieldCurve, October, (2003).

14. Nelsen, R. B., "An introduction to copulas, Springer, (2006) 


\section{APPENDIX 1}

If system is in state $\mathrm{S}_{0}$ then the state transition probability of system to remains in this state will be based on the fact that it should not move in other state. As the failure rate to move in other states are given as
$\lambda_{R}, \lambda_{L}, \lambda_{A}, \lambda_{C L}, \lambda_{C}$ then rate to be in the state $S_{0}$ will be as $\left(1-\lambda_{R} \Delta t\right),\left(1-\lambda_{L} \Delta t\right),\left(1-\lambda_{A} \Delta t\right),\left(1-\lambda_{C L} \Delta t\right),\left(1-\lambda_{C} \Delta t\right)$ .The differential equation for system to be in state $S_{0}$ during time $(\mathrm{t}, \mathrm{t}+\Delta \mathrm{t})$ will be as

$$
\begin{aligned}
& P_{O, S}(t+\Delta t)=\left(1-\lambda_{R} \Delta t\right)\left(1-\lambda_{L} \Delta t\right)\left(1-\lambda_{A} \Delta t\right)\left(1-\lambda_{C L} \Delta t\right)\left(1-\lambda_{C} \Delta t\right) P_{O, S}(t) \\
& \quad+\int_{0}^{\infty} \mu_{0}(x) P_{L}(x, t) d x \Delta t+\int_{0}^{\infty} \mu_{0}(x) P_{C}(x, t) d x \Delta t+\int_{0}^{\infty} \mu_{0}(y) P_{C L}(y, t) d y \Delta t+\int_{0}^{\infty} \mu_{0}(y) P_{R}(y, t) d y \Delta t \\
& \quad+\int_{0}^{\infty} v(z) P_{O, F}(z, t) d z \Delta t+\int_{0}^{\infty} v(z) P_{w}(z, t) d z \Delta t \\
& \Rightarrow L t{ }_{\Delta t \rightarrow 0} \frac{P_{O, S}(t+\Delta t)-P_{O, S}(t)}{\Delta t}+\left(\lambda_{R}+\lambda_{L}+\lambda_{A}+\lambda_{C L}+\lambda_{C}\right) P_{O, S}(t)=\int_{0}^{\infty} \mu_{0}(x) P_{L}(x, t) d x+\int_{0}^{\infty} \mu_{0}(x) P_{C}(x, t) d x \\
& \quad+\int_{0}^{\infty} \mu_{0}(y) P_{C L}(y, t) d y++\int_{0}^{\infty} \mu_{0}(y) P_{R}(y, t) d y+\int_{0}^{\infty} v(z) P_{O, F}(z, t) d z+\int_{0}^{\infty} v(z) P_{w}(z, t) d z \\
& \Rightarrow\left(\frac{\partial}{\partial t}+\lambda_{R}+\lambda_{L}+\lambda_{A}+\lambda_{C L}+\lambda_{C}\right) P_{O, S}(t)=\int_{0}^{\infty} \mu_{0}(x) P_{L}(x, t) d x+\int_{0}^{\infty} \mu_{0}(x) P_{C}(x, t) d x+\int_{0}^{\infty} \mu_{0}(y) P_{C L}(y, t) d y \\
& \quad+\int_{0}^{\infty} \mu_{0}(y) P_{R}(y, t) d y+\int_{0}^{\infty} v(z) P_{O, F}(z, t) d z+\int_{0}^{\infty} v(z) P_{w}(z, t) d z \int_{0}
\end{aligned}
$$

Similarly remaining Equations (2)-(11) for other states can be obtained.

For boundary and initial conditions as:

If at any time the system is in state $S_{i+1}$, after failure from the state $S_{i}, x$ is repair variable; then if repair variable not assigned; then at $\mathrm{x}=0$ the state transition probability of state $\mathrm{S}_{\mathrm{i}+1}$, $=$ failure rate $\times$ state transition probability of its previous state.

Therefore,

$P_{F, O}(0, t)=\lambda_{A} P_{O, S}(t), P_{F, F}(0, t)=\lambda_{S} \lambda_{A} P_{O, S}(t), P_{O, F}(0, t)=\int_{0}^{\infty} v(z) P_{F, F}(z, t) d z$ and so on.

\section{APPENDIX 2}

Availability of the system can be obtained with the help of copula distribution and general distribution in repair as per Equations (57 a) and (57 b), respectively.

In a long run, when the repair is not assigned i.e. treating all repairs to be zero in the expression of $\mathrm{P}_{\text {up }}(\mathrm{s})$ and taking limit ass tends to be zero, the given expression for MTTF can be obtain. Now fixing the failure rates at different values and varying one of them, the MTTF can obtain as given in Table 2 and in Figure 3 . Expected profit, in interval $[0, t)$ can be obtain if service facility is continuously available as per Equation (59). 


\section{Modeling and Availability Analysis of Internet Data Center with various Maintenance Policies}

D. K. Rawala, M. Ram ${ }^{\text {, V. V. Singh }}{ }^{\mathrm{c}}$

a Department of Mathematics, Mewar University Chittorgarh, Rajasthan, India

${ }^{b}$ Department of Mathematics, Graphic Era University, Dehradun, Uttarakhand, India

${ }^{c}$ Department of Mathematics, Yobe State University, Damaturu, Nigeria

PAPER INFO

جكيده

Paper history:

Received 01 March 2013

Received in revised form 19 May 2013

Accepted 22 August 2013

\section{Keywords:}

Reliability Analysis

Internet Data Center (IDC)

Router Failure

Cost Analysis
در اين مقاله، نويسند انان روى تحليل احتمالى يك مركز اطلاعات ايترنت (IDC) كه شامل سرور اصلى پايگاه داده ها

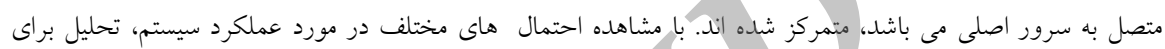
تخمين واقعيت مختلف خصوصيات سيستم انجام شده است. سيستم مى تواند به علت خرابى سرور اضافى قبل از تعمير سرور خايخاه داده ها، خرابى مسيرياب و خرابى سويج به طور كامل با شكست مواجه شود. همجنين، سيستم مى تواند به

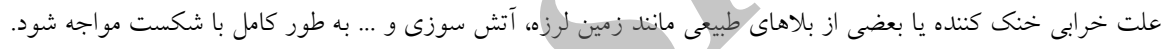
تمام سرعت هاى شكست، هنگامى كه تعميرات (ز دو نوع توزيع با نام هاى رابط خانواده عمومى و كومبل - هو گارد ييروى مى كند، ثابت فرض مى شوند.

doi: 10.5829/idosi.ije.2014.27.04a.10 


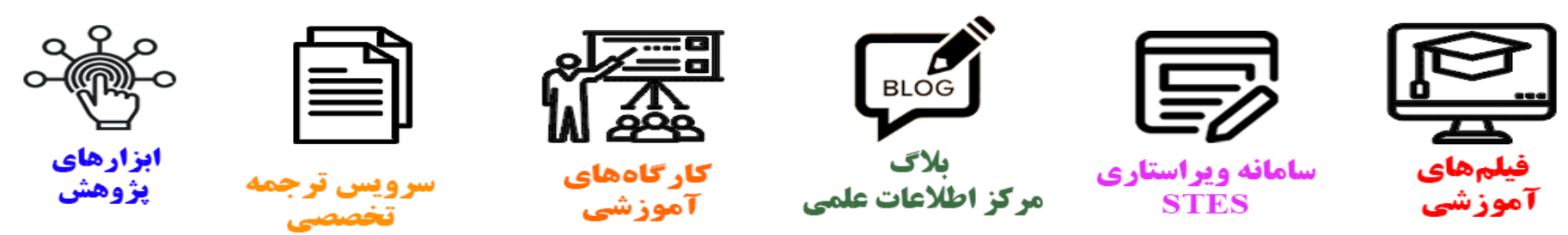

\section{(c)}

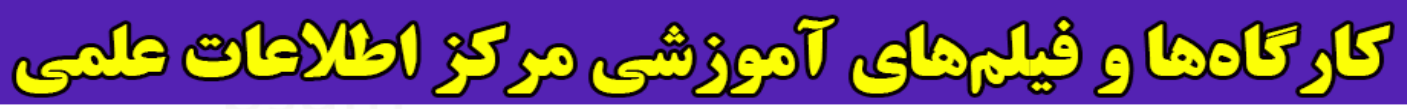
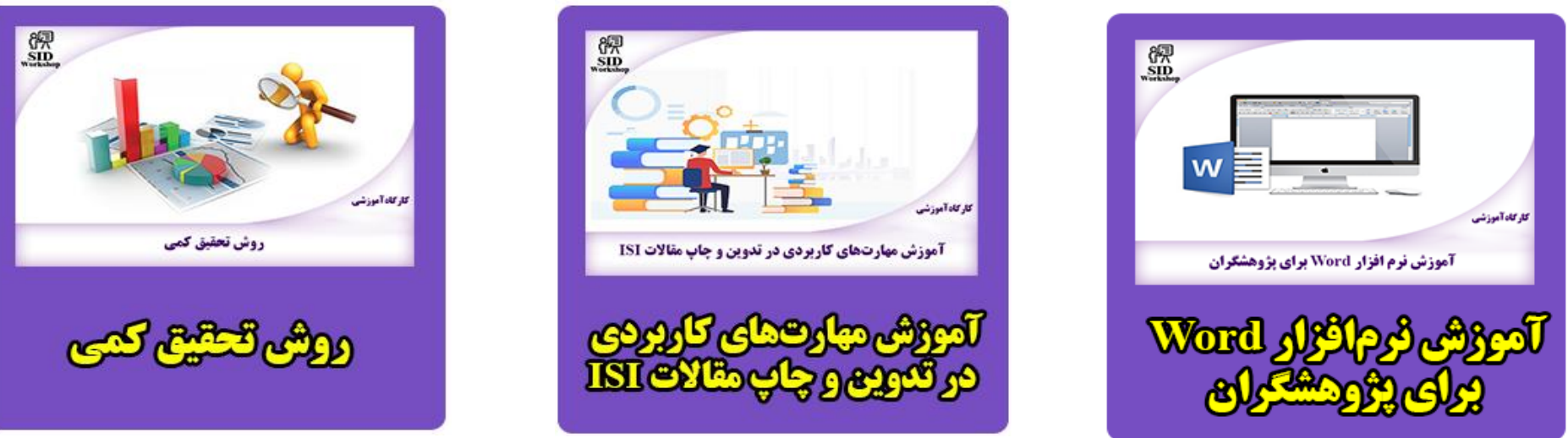